\title{
PENINGKATKAN AKTIVITAS BELAJAR MATEMATIKA MENGGUNAKAN MODEL PEMBELAJARAN KOOPERATIF QUICK ON THE DRAW PADA SISWA KELAS II SEKOLAH DASAR
}

\author{
Sumargiyani \\ Program Studi Pendidikan Matematika \\ FKIP Universitas Ahmad Dahlan Yogyakarta
}

\begin{abstract}
The teacher-centered learning causes less active students during the learning process. Application of learning method using cooperative learning model Quick on the Draw at the second grade students of SD Muhammadiyah Kleco III Yogyakarta can improve learning activities of the students. The Classroom Action Research conducted in three cycles, with the research object is 31 students. Data were collected using observation sheet and interview session. Furthermore, data were analyzed using qualitative descriptive analysis. It is obtained that the percentage of student learning activities from Cycle I is $70.51 \%$ (good), Cycle II is $78.56 \%$ (good) and Cycle III is $87.095 \%$ (very good). Based on the interviews, it is obtained that most of students are interested and feel happy in the learning of mathematics using cooperative learning model Quick on the Draw.
\end{abstract}

Keywords: Activity, learning models, Quick on the Draw

ABSTRAK.Pembelajaran yang berpusat pada guru mengakibatkan siswa kurang aktif selama proses pembelajaran berlangsung. Penerapan pembelajaran dengan menggunakan model pembelajaran kooperatif tipe Quick on theDraw pada siswa kelas II SDMuhammadiyah Kleco III Yogyakarta dapat meningkatkan aktivitas belajar siswa. Penelitian Tindakan Kelas yang dilakukan sebanyak tiga siklus ini, dengan obyek sebanyak 31 siswa. Data dikumpulkan dengan menggunakan lembar observasi dan wawancara. Selanjutnya data dianalisis menggunakan analisis deskriptif kualitatif.Hasil yang diperolehSiklus I persentase aktivitas belajar siswa 70,51\% (baik), Siklus II 78,56\% (baik) dan Siklus III 87,095\% (sangat baik). Berdasarkan hasil wawancara diperoleh keterangan bahwa secara umum siswa tertarik dan merasa senang dalam belajar matematika menggunakan model pembelajaran kooperatif Quick on theDraw.

Kata Kunci: Aktivitas, model pembelajaran, Quick on the Draw

\section{PENDAHULUAN}

Selama ini guru-guru sekolah dasar dituntut untuk melakukan penelitian,salah satunya adalah Penelitian Tindakan Kelas (PTK). Bagi sebagian besar guru Sekolah Dasar (SD) PTK merupakan hal yang baru bagi mereka. 
Beberapa guru juga belum mengetahui bagaimana cara melaksanakan pembelajaran dengan menggunakan pembelajaran kooperatif dengan berbagai macam tipe dalam model pembelajaran. Oleh karena itu penelitian ini dilakukuan untuk memberi pengalaman dan masukan bagi guru SD Muhammadiyah Kleco III bagaimana cara melakukan Penelitian Tindakan Kelas (PTK).

Terkait dengan mata pelajaran yang diberikan di sekolah, beberapa siswa kelas II mengatakan bahwa pelajaran matematika merupakan salah satu pelajaran yang sulit. Pernyataan siswa ini juga dibenarkan oleh guru kelas II yang mengatakan bahwa untuk kelas II hasil ulangan yang memiliki nilai rata-rata rendah adalah Bahasa Jawa dan Matematika. Guru kelas II juga mengatakan sudah berusaha memahamkan materi yang disampaikan pada siswa tetapi hasil yang diperoleh belum maksimal.

Berdasarkan observasi penulis, pembelajaran yang diterapkan guru selama ini menggunakan pembelajaran langsung yaitupembelajaran yang berpusat pada guru dan siswa kurang terlibat aktif dalam pembelajaran. Metode membagi siswa dalam kelompok-kelompok selama pembelajaran juga jarang dilakukan, sehingga terlihat siswa kurang berinteraksi dengan sesama teman selama pembelajaran berlangsung. Ada sebagian siswa yang tidak mau memperhatikan penjelasan guru dan ada yang asyik tidur-tiduran. Hal ini memperlihatkan kurangnya aktifitas siswa dalam belajar dan kurangnya konsentrasi dalam menerima materi pelajaran. Guru kelas II juga mengatakan untuk kelas II siswa lebih banyak yang ramai sendiri saat diterangkan atau saat proses belajar mengajar berlangsung. Pihak guru sudah berusaha mengajak anak untuk belajar dengan menggunakan alat peraga namun hal ini juga belum memperoleh hasil yang optimal.

Terkait dengan masalah di atas, perlu dilakukan perubahan dalam pelaksanaan pendekatan pembelajaran. Keaktifan siswa selama pembelajaran perlu diarahkan pada hal yang positif. Aktivitas siswa dalam belajar perlu ditingkatkan agar siswa dapat berkonsentrasi penuh selama pembelajaran berlangsung. Menurut Asnawi (2011:60) aktif dimaksudkan bahwa dalam proses pembelajaran, guru harus menciptakan suasana sedemikian rupa sehingga siswa 
aktif bertanya, mempertanyakan, dan mengemukakan gagasan. Model pembelajaran yang melibatkan siswa berperan aktif adalah pembelajaran kooperatif. Peran aktif siswa dalam pembelajaran sangatlah penting. Pada hakikatnya, pembelajaran memang merupakan suatu proses aktif dari pembelajaran yang membangun pemikiran dan pengatahuannya (Djamarah, 2010:372).Pembelajaran kooperatif adalah salah satu bentuk pembelajaran yang berdasarkan faham konstruktivis. Pembelajaran kooperatif merupakan strategi belajar dengan sejumlah siswa sebagai anggota kelompok kecil yang tingkat kemampuannya berbeda Isjoni (2012:14).Pada pembelajaran kooperatif para siswa akan duduk bersama dalam kelompok yang beranggotakan empat atau lima orang untuk menguasai materi yang disampaikan guru. Menurut Sanjaya dalam Hamdani (2011:30), pembelajaran kooperatif adalah rangkaian belajar siswa dalam kelompok tertentu untuk mencapai tujuan pembelajaran yang dirumuskan.

Model pembelajaran yang akan diterapkan dalam penelitian ini adalah model pembelajaran kooperatif tipe Quick on the Draw. Menurut Jauhar (2011:52) model pembelajaran kooperatif adalah salah satu bentuk pembelajaran yang berdasarkan paham konstruktivis. Menurut Suprijono (2012:54) model pembelajaran kooperatif adalah konsep yang lebih luas meliputi semua jenis kerja kelompok termasuk bentuk-bentuk yang dipimpin oleh guru atau diarahkan oleh guru. Model pembelajaran kooperatif tipe Quick on the Draw merupakan suatu model pembelajaran yang lebih mengutamakan aktivitas dan kerjasama siswa dalam mencari, menjawab dan melaporakan informasi dari berbagai sumber dalam sebuah suasana permainan yang mengarah pada kecepatan kelompok melalui aktivitas kerja tim dan kecepatan kerja tim. Adanya kerjasama tim yang baik akan membuat siswa merasa senang dalam belajar matematika, sehingga aktivitas siswa untuk belajar matematika lebih meningkat. Menurut Ginnis (Dewanto,2008) pembelajaran kooperatif tipe Quick on the Draw menginginkan agar siswa bekerja sama secara kooperatif pada kelompok-kelompok dengan tujuan untuk menjadi kelompok pertama yang menyelesaikan sekumpulan pertanyaan. Dari pelaksanaan pembelajaran ini, dapat dilihat aktivitas belajar siswa yang meliputi (1) Antusias siswa dalam mengikuti pembelajaran, 
(2)Interaksi siswa dengan guru, (3) Interaksi antar siswa, (4) Kerjasama Kelompok,(5)Aktivitas siswa dalam kelompok dan (6)Partisipasi siswa dalam menyimpulkan hasil pembahasan (Direktorat Pembinaan SMA, 2010).

\section{METODE PENELITIAN}

Penelitian ini merupakan Penelitian Tindakan Kelas (PTK) atau Clasroom Action Research (CAR). Penelitian Tindakan Kelas ini dilakukan oleh guru yang berkolaborasi dengan peneliti. Penelitian ini didesain dengan menggunakan PTK yang terbagi-bagi dalam siklus. Penelitian Tindakan Kelas ini terbagi atas empat tahapan. Prosedur Penelitian Tindakan Kelas terdiri dari tiga siklus dengan setiap siklus terdiri atas dua pertemuan. Adapun jadwal pelaksanaan seperti pada Tabel 1.

Tabel 1. Jadwal pelaksanaan penelitian

\begin{tabular}{|c|c|c|c|l|}
\hline & Pertemuan & Hari / Tanggal & \multicolumn{1}{|c|}{ Waktu } & \multicolumn{1}{|c|}{ Materi } \\
\hline \multirow{2}{*}{$\begin{array}{c}\text { Siklus } \\
\text { I }\end{array}$} & 1 & $\begin{array}{c}\text { Sabtu, 18 } \\
\text { Januari 2014 }\end{array}$ & $07.00-08.10$ & $\begin{array}{l}\text { Operasi Perkalian } \\
\text { (Penjumlahan Berulang) }\end{array}$ \\
\cline { 2 - 5 } & 2 & $\begin{array}{c}\text { Rabu, 22 } \\
\text { Januari 2014 }\end{array}$ & $07.00-08.10$ & Ulangan Harian I \\
\hline \multirow{2}{*}{$\begin{array}{c}\text { Siklus } \\
\text { II }\end{array}$} & 1 & $\begin{array}{c}\text { Jum'at,24 } \\
\text { Januari 2014 }\end{array}$ & $07.00-08.10$ & Konsep Operasi Perkalian \\
\cline { 2 - 5 } & 2 & $\begin{array}{c}\text { Sabtu,25 } \\
\text { Januari 2014 }\end{array}$ & $07.00-08.10$ & Ulangan Harian II \\
\hline \multirow{2}{*}{$\begin{array}{c}\text { Siklus } \\
\text { III }\end{array}$} & 1 & $\begin{array}{c}\text { Rabu, 29 } \\
\text { Januari 2014 }\end{array}$ & $07.00-08.10$ & $\begin{array}{l}\text { Operasi Perkalian (bentuk } \\
\text { cerita) }\end{array}$ \\
\cline { 2 - 5 } & 2 & $\begin{array}{c}\text { Sabtu, 1 } \\
\text { Februari 2014 }\end{array}$ & $07.00-08.10$ & Ulangan Harian III \\
\hline
\end{tabular}

Penelitian ini dilaksanakan di SD Muhammadiyah Kleco III pada Semester Genap Tahun Pelajaran 2013/2014. Subyek penelitian ini adalah seluruh siswa kelas II SD Muhammadiyah Kleco III Tahun Pelajaran 2013/2014 sebanyak 31 siswa. Obyek penelitian adalah peningkatan aktivitas belajar siswa dalam mata pelajaran Matematika melalui model pembelajaran kooperatif tipe Quick on The Draw.

Desain penelitian berdasarkan model PTK Stanford Kemmis dan MC. Taggart yang terdiri dari tahap-tahap perencanaan, tindakan, pengamatan dan 
refleksi. Peneliti menggunakan lembar observasi untuk mengobservasi dan mengumpulkan data tentang aktivitas belajar siswa. Selanjutnya data dianalisis dengan menggunakan metode deskriptif kualitatif untuk menentukan kriteria tingkat aktivitas belajarsiswa selama pembelajaran.

\section{HASIL DAN PEMBAHASAN}

Selama kegiatan pembelajaran matematika menggunakan model pembelajaran kooperatif tipe Quick on The Draw dilakukan pengamatan tentang aktivitas belajar siswa. Data aktivitas belajar tersebut selanjutnya dianalisis untuk mengetahui ada tidaknya peningkatan aktivitas belajar siswa pada mata pelajaran Matematika. Hasil dari pengamatan selama tiga siklus mengenai aktivitas belajar siswa ditunjukkan pada Tabel 2 berikut ini.

Tabel 2.Persentase aktivitas belajarsiswa pada Siklus I, Siklus II dan Siklus III

\begin{tabular}{|c|c|c|c|c|}
\hline \multirow{2}{*}{ Indikator } & \multicolumn{3}{|c|}{ Persentase } & \multirow{2}{*}{ Keterangan } \\
\hline & Siklus I & Siklus II & Siklus III & \\
\hline $\begin{array}{l}\text { Antusias siswa dalam } \\
\text { mengikuti pembelajaran }\end{array}$ & 77 & 89,5 & 96,9 & Meningkat \\
\hline Interaksi siswa dengan guru & 65 & 76,5 & 85,1 & Meningkat \\
\hline Interaksi antar siswa & 50 & 60 & 77,2 & Meningkat \\
\hline Kerjasama kelompok & 69,5 & 75,5 & 83,55 & Meningkat \\
\hline $\begin{array}{l}\text { Aktivitas siswa dalam } \\
\text { kelompok }\end{array}$ & 85 & 88.5 & 93 & Meningkat \\
\hline $\begin{array}{l}\text { Partisipasi siswa dalam } \\
\text { menyimpulkan pembahasan }\end{array}$ & 87 & 89,5 & 89,66 & Meningkat \\
\hline $\begin{array}{l}\text { Rata-rata persentase } \\
\text { aktivitas belajar siswa }\end{array}$ & 70,505 & 78,56 & 87,095 & Meningkat \\
\hline
\end{tabular}

Hasil rata-rata persentase aktivitas belajar siswa pada Tabel 2, selanjutnya dikriteriakan atau dikategorikan dengan menggunakan Tabel 3.

Tabel 3.Kualifikasi hasil persentase skor motivasi belajar mahasiswa

\begin{tabular}{c|c}
\hline Persentase Motivasi Belajar & Tingkat Motivasi Belajar \\
\hline $81-100$ & Sangat baik \\
\hline $61-80$ & Baik \\
\hline $41-60$ & Cukup \\
\hline $21-40$ & Kurang \\
\hline $0-20$ & Sangat kurang \\
\hline
\end{tabular}


Setelah data pada Tabel 2. dikategorikan menggunakan Tabel 3. diperoleh hasil pada siklus I sebesar 70,505 \% termasuk kategori cukup, pada siklus II sebesar $78,56 \%$ termasuk kategori baik dan pada siklus III sebesar 87,095\% dengan kategori sangat baik. Secara grafik dapat digambarkan pada Gambar 1.

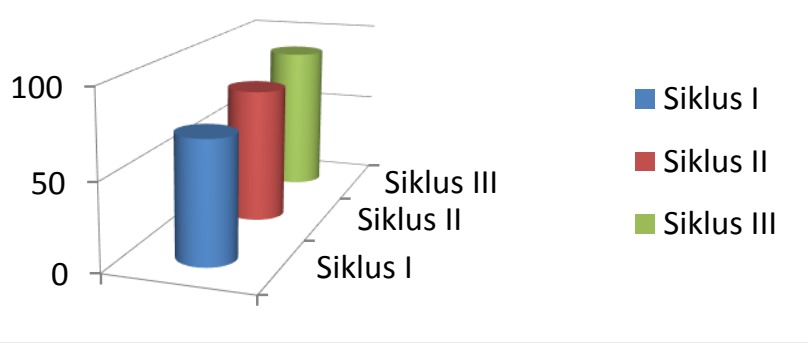

Gambar 1. Persentase Rata-rata Aktivitas Belajar per Siklus

Untuk melihat peningkatan tiap indikator dari Siklus I ke Siklus II ke Siklus III dapat dilihat pada Gambar 2.

Hasil Penelitian Tindakan Kelas yang terdiri dari siklus I, II, dan III menggunakan model pembelajaran kooperatif tipe Quick on the Drawcukup berjalan lancar siswa waktu dikelompokkan terlihat ramai, akan tetapi akan tetapi saat mengerjakan soal yang ada di kartu, siswa-siswa terlihat bersemangat dan ingin menyelesaikan paling awal.

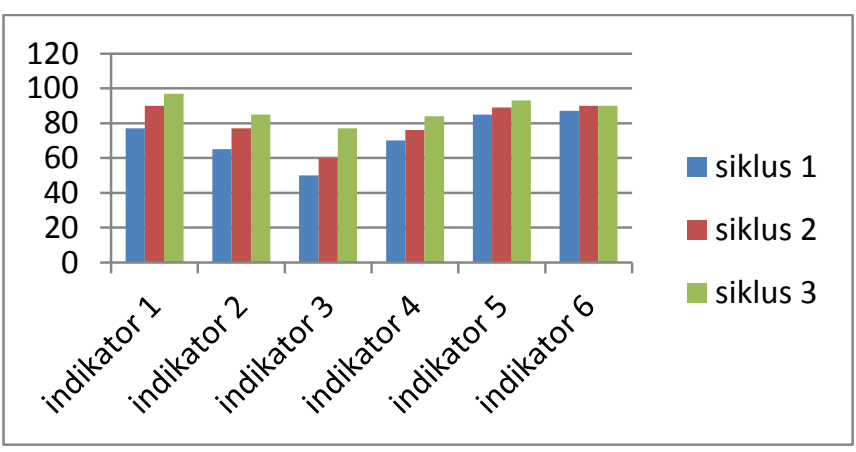

Gambar 2. Grafik persentase peningkatan aktivitas belajar siswa Siklus I, II, III

Berdasarkan hasil observasi, interaksi antar siswa dalam mengikuti pembelajaran cukup. Sedangkan antusias siswa dalam mengikuti pembelajaran, interaksi siswa dengan guru dan kerjasama kelompok dalam kriteria baik, aktivitas siswa dalam kelompok dan partisipasi siswa dalam menyimpulkan hasil pembahasan sangat baik. Aktivitas belajar siswa dalam kelompok dan partisipasi siswa dalam 
menyimpulkan hasil pembahasan sangat baik, karena mereka masing-masing kelompok ingin cepat menyelesaikan soal yang diberikan agar menjadi juara dan mendapat hadiah. Siswa-siswa tanpa takut mau mengemukakan jawaban yang telah diperoleh saat pembahasan soal. Berdasarkan hasil observasi pada saat pembelajaran matematika, rata-rata persentase aktivitas siswa pada Siklus I adalah $70,51 \%$ dengan kriteria baik. Berdasarkan dari hasil tes siklus I diperoleh rata-rata nilai tertinggi sebesar 100, nilai terendah 90 persentase ketuntasan klasikal 100\% atau $100 \%$ siswa tuntas belajar individu. Hal ini menunjukkan bahwa hasil tes sangat baik.

Pada Siklus II proses pembelajaran menggunakan model pembelajaran kooperatif tipe Quick on the Draw. Berdasarkan hasil observasi Siklus II antusias siswa dalam mengikuti pembelajaran, interaksi siswa dengan guru, interaksi antar siswa, dan kerjasama kelompok aktivitas belajar dalam kriteria baik. Sedangkan indikator yang lain dalam kriteria sangat baik. Berdasarkan hasil observasi saat pembelajaran matematika rata-rata persentase aktivitas siswa pada Siklus II adalah $78,56 \%$ dengan kriteria baik. Berdasarkan dari hasil tes Siklus II diperoleh nilai tertinggi sebesar 100 nilai terendah 90 dengan persentase ketuntasan klasikal $100 \%$ atau sebanyak 31 siswa tuntas belajar individu. Hal ini menunjukkan bahwa ketuntasan individu siswa maupun ketuntasan klasikal sudah tercapai.

Pada Siklus III, hasil observasi menunjukkan bahwa interaksi antar siswa sudah baik, sedangkan indikator yang lain sangat baik. Hal ini dikarenakan semua siswa sudah bisa menerima bimbingan guru dibandingkan pertemuan-pertemuan sebelumnya. Siswa terlihat antusias dan bersemangat ketika mengikuti pembelajaran. Ketika terdapat materi yang kurang jelas, siswa bertanya pada guru dan mereka sangat memperhatikan penjelasan guru. Berdasarkan hasil observasi pada saat pembelajaran matematika rata-rata persentase aktivitas siswa pada Siklus III adalah 87,095\% dengan kriteria sangat baik. Berdasarkan dari hasil tes Siklus III diperoleh rata-rata nilai tertinggi 100 nilai terendah 90 dengan persentase ketuntasan klasikal 100\%.

Pembelajaran matematika menggunakan model pembelajaran kooperatif tipe Quick on the Draw memperlihatkan terjadi peningkatan persentase aktivitas 
belajar siswa dari Siklus I, II dan III. Hal ini dapat dilihat pada Tabel 2. Selain itu, hasil tes (ulangan harian) pada tiap siklusnya juga memperlihatkan terjadinya ketuntasan klasikal.Hal ini dapat dilihat pada Tabel 4 berikut.

Tabel 4. Peningkatan Tes Siklus I, II, dan III

\begin{tabular}{l|c|c|c}
\hline \multicolumn{1}{c|}{ Hasil Evaluasi } & Siklus I & Siklus II & Siklus III \\
\hline Siswa yang tuntas & 100 & 100 & 100 \\
\hline Nilai tertinggi & 100 & 100 & 100 \\
\hline Nilai terendah & 90 & 90 & 90 \\
\hline Ketuntasan klasikal & $\mathbf{1 0 0 \%}$ & $\mathbf{1 0 0 \%}$ & $\mathbf{1 0 0 \%}$ \\
\hline
\end{tabular}

Dalam penelitian ini, selain menggunakan data hasil observasi peneliti juga menggunakan data berupa wawancara yang dilakukan dengan beberapa siswa kelas II setiap akhir Siklus I, II dan III. Wawancara dilakukan untuk mengetahui tanggapan siswa mengenai pembelajaran matematika dengan menggunakan model pembelajaran kooperatif tipe Quick on the Draw. Respon siswa terhadap pembelajaran matematika menggunakan model pembelajaran kooperatif tipeQuick on the Draw sangat baik, seperti terlihat dari hasil wawancara dengan beberapa siswa. Berdasarkan hasil wawancara diperoleh hasil sebagai berikut:

1. Respon yang positif dari siswa terhadap pembelajaran matematika menggunakan model pembelajaran kooperatif tipeQuick on the Draw.

2. Model pembelajaran kooperatif tipeQuick on the Draw dapat meningkatkan aktivitas belajar siswa dalam proses pembelajaran matematika.

3. Dari penggunaan model pembelajaran kooperatif tipeQuick on the Draw, siswa menjadi lebih bersemangat dalam belajar matematika. Kegiatan pembelajaran matematika lebih menyenangkan dan lebih mudah.

Dari keseluruhan data di atas tujuan penelitian telah tercapai pada Siklus III, sehingga penelitian dianggap selesai dan hasil penelitian menunjukkan peningkatan aktivitas belajar siswa kelas II Semester Genap SD Muhammadiyah Kleco III YogyakartaTahun Pelajaran 2013/2014 dengan menggunakan model pembelajaran kooperatif tipe Quick on the Draw. Dengan demikian, hipotesis tindakan terbukti. 


\section{KESIMPULAN DAN SARAN}

Berdasarkan penelitian yang telah dilaksanakan pada siswa kelas II Semester Genap di SD Muhammadiyah Kleco III Yogyakarta Tahun Pelajaran 2013/2014 pada sub pokok bahasan Operasi Perkalian diperoleh kesimpulan bahwamodel pembelajaran kooperatif tipe Quick on the Draw dapat meningkatkan aktivitas belajar siswa. Hal ini terbukti dari persentase aktivitas belajar siswa mengalami peningkatan pada setiap siklusnya. Pada siklus I rata-rata persentase hasil observasi aktivitas belajar siswa sebesar 70,51\% dengan kriteria baik. Pada Siklus II rata-rata persentase hasil observasi aktivitas belajar siswa meningkat menjadi 78,56\% dengan kriteria baik. Kemudian pada Siklus III ratarata persentase hasil observasi aktivitas belajar siswa meningkat menjadi 87,095\% dengan kriteria sangat baik. Artinya dengan menggunakan model pembelajaran kooperatif tipe Quick on the Draw aktivitas belajar siswa mengalami peningkatan.

Pembelajaran matematika menggunakan model pembelajaran kooperatif tipe Quick on the Draw mendapat respon yang positif dari siswa. Hal ini dibuktikan dari hasil wawancara dengan beberapa siswa, secara garis besar menyatakan bahwa model pembelajaran kooperatif tipe Quick on the Draw dapat meningkatkan aktivitas belajar siswa dalam proses pembelajaran matematika. Melalui model pembelajaran kooperatif tipe Quick on the Draw siswa menjadi lebih bersemangat dalam belajar matematika, kegiatan pembelajaran matematika juga menjadi lebih menyenangkan dan lebih mudah. Dengan demikian, model pembelajaran ini dapat dijadikan referensi dan masukan dalam proses pembelajaran sebagai variasi pembelajaran agar siswa tidak cepat jenuh dan tentunya dapat meningkatkan aktivitas belajar siswa.

\section{UCAPAN TERIMA KASIH}

Selama proses penelitian berlangsung hingga tersusunnya laporan penelitian dan makalah ini tidak lepas dari bantuan tenaga maupun dukungan dari berbagai pihak. Pada kesempatan ini kami mengucapkan banyak terima kasih kepada : 
a. Bapak Dr. Kasiyarno,M.Hum, Rektor Universitas Ahmad Dahlan Yogyakarta, yang telah memberikan kesempatan untuk melakukan penelitian.

b. Ibu Dra. Trikinasih Handayani,M.Si, Dekan FKIP Universitas Ahmad Dahlan Yogyakarta, yang telah memberikan ijin untuk melakukan penelitian.

c. Bapak Drs.Abdul Taram,M.Si, Kaprodi Pendidikan Matematika FKIP Universitas Ahmad Dahlan Yogyakarta, yang telah mendorong penulis untuk melakukan penelitian.

d. Bapak Dr.Widodo,M.Si, Kepala LPP Universitas Ahmad Dahlan Yogyakarta, yang telah mengijinkan penulis melakukan penelitian.

e. Bapak Dr.Suparman,M.Si.DEA, selaku reviewer penelitian ini.

f. Ibu Siti Nurjannah Hartati,S.Pd, Kepala Sekolah SD Muhammadiyah Kleco III Yogyakarta.

g. Ibu Suratmi,S.Pd, selaku guru kelas II SD Muhammadiyah Kleco III Yogyakarta, atas bantuan dan kerjasamanya yang baik.

\section{DAFTAR PUSTAKA}

Asnawi, J. M. (2011) 7 Tips Aplikasi PAKEM (Pembelajaran Aktif, Kreatif, Efektif, dan Menyenangkan) Menciptakan Metode Pembelajaran yang Efektif dan Berkualitas. DIVA Press, Yogyakarta.

Direktorat Jendral Manajemen Pendidikan Dasar dan Menengah (2010) Pelaksanaan Penilaian dalam Implementasi KTSP KementrianPendidikan Nasional, Direktorat Pembinaan, Jakarta.

Djamarah, S. B. (2010) Guru dan Anak Didik dalam Interaksi Edukatif Suatu Pendekatan Teoritis Psikologis, Rineka Cipta, Jakarta.

Ginnis, P. dan Wasi Dewanto (2008) Trik dan Taktik Mengajar, Indeks, Jakarta. Hamdani (2011) Strategi Belajar Mengajar.Pustaka Setia, Bandung.

Isjoni (2012) Pembelajaran Kooperatif Meningkatkan Kecerdasan Komunikasi Antar Peserta Didik, Pustaka Pelajar,Yogyakarta 